\title{
Acute lower respiratory tract infections and associated factors among under-five children visiting Wolaita Sodo University Teaching and Referral Hospital, Wolaita Sodo, Ethiopia
}

Birhanu Wondimeneh Demissie ${ }^{1 *}$, Esayas Aydiko Amele1, Yibeltal Asmamaw Yitayew ${ }^{2}$ and Zemen Mengesha Yalew ${ }^{3}$

\begin{abstract}
Background: Lower respiratory infections are a leading cause of morbidity and mortality worldwide, particularly in children younger than 5 years. Even if the burden of lower respiratory infections in children under 5 years old had decreased dramatically in the last 10 years, it is still the main cause of morbidity and mortality in children under-5 years old in developing countries, so the aim of this study was to assess the magnitude of lower respiratory tract infections and associated factors among under-five children visiting Wolaita Sodo University Teaching and Referral Hospital.
\end{abstract}

Method: A cross-sectional study was conducted from 1st to 30th April 2019, among under-five child/mother or caretaker pairs visiting Wolaita Sodo University Teaching and Referral Hospital. Child/mother or caretaker pairs who visits outpatient department for curative care service or follow up were recruited for the study. Data were collected using a semi-structured pre-tested interviewer-guided questionnaire. Epi-info (version 7.1.2.0) was used for data entry, and Statistical Package for Social Sciences version 20 was used for analysis. Bivariate and multivariate logistic regression, crude and adjusted odds ratios with their $95 \%$ confidence intervals was computed. Finally, a p-value $\leq 0.05$ was used to identify variables that had a significant association with acute lower respiratory infection.

Result: A total of 414 child/mother or caretaker pairs were recruited for the study. The magnitude of acute lower respiratory infections among under-five children was $40.3 \%$ (95\% Cl: 35.7- 44.9\%). Unvaccinated children (AOR: 2 , $95 \% \mathrm{Cl}$, (1.27-3.16)), non-exclusive/replacement feeding (AOR: 1.85, $95 \%$ Cl, (1.18-2.91)), households mainly used unclean fuel for cooking (AOR: 2.12, $95 \% \mathrm{Cl}$, (1.07-4.19)), absence of separate kitchen (AOR: 1.7, 95\% Cl, (1.09-2.65)), and absence of window in the kitchen room (AOR: 1.69, $95 \% \mathrm{Cl},(1.07-2.68)$ ) showed significant association with acute lower respiratory infection.

Conclusions: The magnitude of acute lower respiratory tract infections among under-five children visiting outpatient department was $40.3 \%$. Unvaccinated children, non-exclusive/replacement feeding, using unclean fuel for

\footnotetext{
*Correspondence: birhanuwondimeneh@gmail.com

1 School of Nursing, College of Health Science and Medicine, Wolaita

Sodo University, Sodo, Ethiopia

Full list of author information is available at the end of the article
}

(C) The Author(s) 2021. Open Access This article is licensed under a Creative Commons Attribution 4.0 International License, which permits use, sharing, adaptation, distribution and reproduction in any medium or format, as long as you give appropriate credit to the original author(s) and the source, provide a link to the Creative Commons licence, and indicate if changes were made. The images or other third party material in this article are included in the article's Creative Commons licence, unless indicated otherwise in a credit line to the material. If material is not included in the article's Creative Commons licence and your intended use is not permitted by statutory regulation or exceeds the permitted use, you will need to obtain permission directly from the copyright holder. To view a copy of this licence, visit http://creativecommons.org/licenses/by/4.0/. The Creative Commons Public Domain Dedication waiver (http://creativeco mmons.org/publicdomain/zero/1.0/) applies to the data made available in this article, unless otherwise stated in a credit line to the data. 
cooking, absence of a separate kitchen, and absence of window in the kitchen showed significant association with acute lower respiratory infection. Therefore, special attention should be given to the environmental sanitation and family health components of health extension packages.

Keywords: Acute, Respiratory tract infection, Associated factors, Under-five, Ethiopia

\section{Background}

Acute lower respiratory tract infections (LRTIs) are any infections in the lungs or below the voice box, which include pneumonia, bronchitis, and bronchiolitis [1]. To date, pneumonia is the most common type of lower respiratory tract infection (LRTI) and globally, 150 million new episodes of pneumonia are identified per year worldwide, more than $90 \%$ of which occur in developing countries [2,3]. Viruses are the most common cause of pneumonia in infants and young children, and the most frequent symptoms and signs are coughs, increased respiratory rate, fever, breathing difficulty, runny nose, and indrawn chest wall in more severe disease [3-6].

Lower respiratory tract infections (LRTIs) are the leading cause of morbidity and mortality worldwide, particularly in children younger than five years [7, 8]. Globally, LRTIs cause 704 000 deaths, and the highest under-five LRTI mortalities were in sub-Saharan Africa. Even if the burden of LRTIs in children under-five years of age has decreased dramatically in the last ten years, it is still the main cause of death in developing countries [8-10]. Each year, more than 2 million children under-five years of age die due to pneumonia in developing world, and $43 \%$ of global under-five deaths from acute LRTIs occur in India, Nigeria, Democratic Republic Congo and Ethiopia [11]. In Ethiopia in 2015, 25,970 under-five children died due to LRTIs, and $14,148.3$ were caused by pneumonia [8].

Different factors were identified for the increased risk of LRTIs in children. Of these, poverty, restricted family income, low parental education level, low birth weight, malnutrition, lack of breastfeeding, maternal literacy, smoking, cow dung use for fuel, low socio-demographic status, solid fuels for cooking and heating, immune impaired populations, improved toilet facilities, season, and residence $[8,10,12,13]$. Similarly, the risk of death from LRTIs will be determined by very severe pneumonia, age below two months, diagnosis of Pneumocystis Carinii, chronic underlying diseases including HIV/ AIDS, severe malnutrition, young maternal age, low maternal education, low socioeconomic status, secondhand smoke exposure, and indoor air pollution [14].

Widespread immunization against influenza, measles, bacilli Calmette-Guerin (BCG), and now pneumococcus have been related to the decline of LRTIs in children [3]. Likewise, vaccines prevent an estimated 2.5 million deaths among under-five children every year. However, one child dies every $20 \mathrm{~s}$ from a disease that could have been prevented by a vaccine [15]. Ethiopian children suffer four to eight episodes of acute LRTIs on average every year, with the highest occurrence in urban areas of overcrowded living conditions [7]. In Ethiopia, only $39 \%$ received all vaccinations at some time, and $22 \%$ were vaccinated by the appropriate age [16], this low immunization coverage will result in an increased risk of LRTI morbidity and mortality.

Even if Ethiopia has achieved millennium development goals (MDG) 4 by 2013, LRTIs are one of the most common causes of under-five children mortality [17]. To achieve the sustainable development goal (SDG) 3 of ending preventable deaths of new-borns and under-five children by 2030 , efforts to reduce deaths due to lower respiratory tract infection should remain a top priority $[18,19]$. Therefore, this study aimed to assess the magnitude of acute lower respiratory tract infections and associated factors among under-five children visiting Wolaita Sodo University Teaching and Referral Hospital (WSUTRH), 2019.

\section{Methods \\ Study design, area and period}

An institution-based cross-sectional study was conducted from 1st to 30th April 2019, at Wolaita Sodo University Teaching and Referral Hospital (WSUTRH). Wolaita Sodo University Teaching and Referral Hospital is found in Sodo town, which is located $157 \mathrm{~km}$ from the regional capital city, Hawassa, and $327 \mathrm{~km}$ from the capital city of Ethiopia, Addis Ababa. According to the Wolaita Zone Health Department information 2019, the estimated population of Wolaita Zone is approximately $2,020,386$, of which approximately 983,991 are males and $1,030,396$ are females. The hospital gives service to more than 3 million people in the catchment area of wolaita and Dawro, has 350 inpatient beds, and $450-500$ patients visit the hospital per day [20].

\section{Populations Source population}

All under-five child/mother or caretaker pairs visiting WSUTRH pediatric outpatient department (OPD) for curative care service or follow up. 


\section{Study population}

Randomly selected under-five child/mother or caretaker pairs visited WSUTRH pediatric outpatient department (OPD) from 1st to 30th April 2019.

\section{Sample size determination}

The sample size was calculated using a single population proportion formula and since there was no proportion of LRTI with similar population we calculate with the assumption of $50 \%$ under-five prevalence of acute LRTIs to obtain the largest sample size, with a $95 \%$ confidence interval and $5 \%$ marginal error.

By considering a $10 \%$ non-response rate, the final sample size was 422 child/mother pairs.

\section{Sampling procedure}

The estimated number of child/mother or care taker pairs visited under-five OPDs in the study period was 1050 based on the last six months of patient flow and then $\mathrm{k}$ was calculated, $\mathrm{k}=1050 / 422 \sim 2$, participants were selected using a systematic random sampling technique $(\mathrm{k}=2)$, that is every two client (child/mother pair) visiting under five OPD until the required sample size was obtained.

\section{Data collection instrument}

A face-to-face interview was conducted using a structured questionnaire that was adopted and modified from previous studies [21-27]. The questionnaire comprises sociodemographic factors, maternal and child factors, environmental factors, and the outcome variable acute LRTIs. Length board ( $<2$ years) or portable stadiometer ( $\geq 2$ years) and portable digital weight scale were used to measure the height and weight of the child, respectively.

\section{Data collection procedure and quality control}

The data were collected by four BSc nurses and supervised by two MSc pediatrics and child health nurse professionals. Training was given for data collectors and supervisors for two days, and pre-test was conducted in $5 \%$ [21] of the final sample size in Sodo Christian hospital. Both supervisors and data collectors were closely followed for the data collection process, and all filled questionnaires were checked every day, and errors were corrected accordingly. The weight of the child was measured using a well-calibrated, portable digital weight scale without shoes and wearing light clothes. Moreover, reliability of the weight scale was checked before each measurement.

\section{Data entry and analysis}

The collected data were checked for completeness, consistency, and accuracy, entered into EPI data version 3.1 and exported to Statistical Package for Social Sciences version (SPSS) 22.0 for data analysis. Descriptive statistics with percentages, frequency distributions, measures of central tendency, and dispersion were used to describe the data. Bivariate logistic regression was used to check variables having an association with ALRIs, and those variables found to have a $\mathrm{p}$-value of $<0.2$ were further analyzed using multiple logistic regressions. Odds ratios (ORs) with $95 \%$ CIs were computed and variables with a $\mathrm{p}$-value $<0.05$ were considered significant variables. Model fitness was checked with the Hosmer and Lemeshow goodness-of-fit test, which was $\mathrm{p}=0.767$.

\section{Operational definitions Acute lower respiratory tract infections}

A child presented with cough, fever, rapid or difficulty breathing in the last two weeks and was diagnosed with acute LRTIs (pneumonia or acute bronchitis or bronchiolitis) by the physician.

Acute nutritional status of the child; was assessed based on weight-for-height Z- score which was calculated with WHO AnthroPlus software.

Sever acute malnutrition; those who had WHO Z score of $<-3$ SD.

Moderate acute malnutrition; those who had WHO $\mathrm{Z}$ score of -3 to $<-2 \mathrm{SD}$.

Mild acute malnutrition/normal; those who had WHO Z score of $\geq-2$ SD.

\section{Main cooking fuel \\ Unclean fuel: using wood, animal dung, charcoal, crop wastes, kerosene stove and kerosene lamp [28]. \\ Clean fuel: use of electricity, gas, ethanol, and solar [28].}

\section{Breast feeding}

Exclusive breast feeding: infants receive only breast milk for the first six months or receive only breast milk until the time of assessment for infants < six months.

Non-exclusive or replacement feeding: Giving food or fluid (milk) alone or in addition to breast milk for infants $<$ six months.

Immunization status

Immunized for age: Took all vaccines appropriate for age based on the immunization schedule. 
Incomplete: defaulters or those who were not vaccinated based on the immunization schedule.

Not vaccinated: a child who did not take the vaccine at all.

\section{Result}

\section{Sociodemographic characteristics}

A total of 414 child/mother or caretaker pairs had participated in the study, which resulted in a $98.1 \%$ response rate. The mean age and standard deviation of children and mothers were $21.3 \pm 14.13$ months and $29 \pm 5.8$ years, respectively. Nearly half $(46.4 \%)$ of children were aged $\geq 24$ months, the majority (54.6\%) of children were male, and $59.4 \%$ were urban dwellers. Nearly half of the respondents (49\%) were protestant in religion, $32.6 \%$ were unable to read and write, and $57.7 \%$ were housewives in occupation. Nearly all (93\%) children's parents lived together, and the average monthly income of the family was $2356 \pm 1316$ Ethiopian birr (Table 1 ).

\section{Maternal and child factors}

The mean and standard deviation of children's weight and height were $10.2 \pm 2.9 \mathrm{~kg}$ and $78.4 \pm 12.4 \mathrm{~cm}$, respectively. The majority (58.2\%) of children did not have a history of upper respiratory tract infection (URTI), and $34.1 \%$ of children did not take immunization at all. Over two-thirds of children $(70.5 \%)$ were exclusively breastfed in the first six months, $29 \%$ of children took vitamin A in the last months, and $4.1 \%$ of children had severe wasting. Only $3.4 \%$ of children had parents with chronic illness, $59.4 \%$ of mothers took iron folate, $64.5 \%$ of mothers took extra food during pregnancy, and $4.1 \%$ of mothers had sexually transmitted infections (STIs) during pregnancy (Table 2).

\section{Environmental factors}

Half of the respondents (49.5\%) had a family size of $\leq 4$ people, there was a smoker in $6 \%$ of households, and $82.4 \%$ of children were cared for by their mothers. The majority of households (67.4\%) had a separate kitchen, $71 \%$ of cooking areas had windows, and $76.2 \%$ of households used unclean fuel for cooking (Table 3).

\section{Magnitude of acute lower respiratory tract infections}

The magnitude of acute LRTIs was found 40.3\% (95\% CI: $35.7-44.9 \%)$.

\section{Factors associated with acute lower respiratory tract infections}

In the bivariate analysis, parents living together, history of URTI, vaccination status, breastfeeding in the first six months, a person who cared for the child, main cooking fuel type, a smoker in the house, a separate
Table 1 Sociodemographic characteristics of acute lower respiratory infections among under-five children/mother or caretaker pair attended at WSUTRH, $2019(n=414)$

\begin{tabular}{|c|c|c|}
\hline Variable $N=414$ & Frequency $(\mathrm{N})$ & Percent (\%) \\
\hline \multicolumn{3}{|l|}{ Age of the child } \\
\hline $2-5$ months & 44 & $10.6 \%$ \\
\hline 6-11 months & 77 & $18.6 \%$ \\
\hline $12-23$ months & 101 & $24.4 \%$ \\
\hline 24-59 months & 192 & $46.4 \%$ \\
\hline \multicolumn{3}{|l|}{ Sex of the child } \\
\hline Male & 226 & $54.6 \%$ \\
\hline Female & 188 & $45.4 \%$ \\
\hline \multicolumn{3}{|l|}{ Age of the mother } \\
\hline$\leq 24$ & 85 & $20.5 \%$ \\
\hline $25-34$ & 264 & $63.8 \%$ \\
\hline$\geq 35$ & 65 & $15.7 \%$ \\
\hline \multicolumn{3}{|l|}{ Residence } \\
\hline Urban & 246 & $59.4 \%$ \\
\hline Rural & 168 & 40.65 \\
\hline \multicolumn{3}{|l|}{ Religion of the respondent } \\
\hline Protestant & 203 & $49 \%$ \\
\hline Orthodox & 122 & $29.5 \%$ \\
\hline Catholic & 46 & $11.1 \%$ \\
\hline Muslim & 43 & $10.4 \%$ \\
\hline \multicolumn{3}{|l|}{ Educational status of mother } \\
\hline Unable to read and write & 135 & $32.6 \%$ \\
\hline Able to write and read & 130 & $31.4 \%$ \\
\hline Primary school & 79 & $19.1 \%$ \\
\hline Secondary school & 41 & $9.9 \%$ \\
\hline Diploma and above & 29 & $7 \%$ \\
\hline \multicolumn{3}{|l|}{ Occupation of the mother } \\
\hline House wife & 293 & $57.7 \%$ \\
\hline Government employee & 31 & $7.5 \%$ \\
\hline Private business & 33 & $8 \%$ \\
\hline Student & 3 & $0.7 \%$ \\
\hline Farmer & 29 & $7 \%$ \\
\hline Daily labor & 79 & $19.1 \%$ \\
\hline \multicolumn{3}{|l|}{ Does parents live together } \\
\hline Yes & 385 & $93 \%$ \\
\hline No & 29 & $7 \%$ \\
\hline \multicolumn{3}{|l|}{ Family income } \\
\hline$\leq 1999$ ETB & 149 & 36 \\
\hline 2000-3499 ETB & 189 & 45.7 \\
\hline$\geq 3500$ ETB & 76 & 18.4 \\
\hline
\end{tabular}

kitchen, a window for the kitchen, and nutritional status of the child were factors that had a p-value $<0.2$. Variables that had a p-value of $<0.2$ in the bivariate analysis were further analysed using multivariate logistic regression. The results of this analysis showed that immunization status, breastfeeding in the first six 
Table 2 Maternal and child factors of acute lower respiratory infections among under-five children attended at WSUTRH, 2019 $(n=414)$

\begin{tabular}{|c|c|c|}
\hline Variable $\mathrm{N}=414$ & Frequency $(\mathrm{N})$ & Percent (\%) \\
\hline \multicolumn{3}{|l|}{ History of URTI within 2 weeks } \\
\hline Yes & 173 & $41.8 \%$ \\
\hline No & 241 & $58.2 \%$ \\
\hline \multicolumn{3}{|l|}{ Immunization } \\
\hline Immunized & 232 & $56 \%$ \\
\hline Incomplete & 41 & $9.9 \%$ \\
\hline Not vaccinated & 141 & $34.1 \%$ \\
\hline \multicolumn{3}{|c|}{ BF in the first 6 months (current for $<6$ months) } \\
\hline Exclusive BF & 292 & $70.5 \%$ \\
\hline Non-exclusive/ replacement feeding & 122 & $29.5 \%$ \\
\hline \multicolumn{3}{|l|}{ Vitamin A supplementation } \\
\hline Yes & 120 & $29 \%$ \\
\hline No & 250 & $60.4 \%$ \\
\hline Not eligible & 44 & $10.6 \%$ \\
\hline \multicolumn{3}{|l|}{ Nutritional status of the child } \\
\hline Sever acute malnutrition & 17 & $4.1 \%$ \\
\hline Moderate acute malnutrition & 30 & $7.2 \%$ \\
\hline Mild/normal & 367 & $88.7 \%$ \\
\hline \multicolumn{3}{|l|}{ Parental chronic illness } \\
\hline Yes & 14 & $3.4 \%$ \\
\hline No & 400 & $96.6 \%$ \\
\hline \multicolumn{3}{|l|}{ Maternal iron folate intake } \\
\hline Yes & 246 & $59.4 \%$ \\
\hline No & 168 & $40.6 \%$ \\
\hline \multicolumn{3}{|l|}{ Take extra meal during pregnancy } \\
\hline Yes & 267 & $64.5 \%$ \\
\hline No & 147 & $35.5 \%$ \\
\hline \multicolumn{3}{|l|}{ STI during pregnancy } \\
\hline Yes & 17 & $4.1 \%$ \\
\hline No & 397 & $95.9 \%$ \\
\hline
\end{tabular}

months, main cooking fuel, separate kitchen, and window for the kitchen were significantly associated with acute LRTIs (Table 4).

Unvaccinated children were 2 times more likely to be affected by acute LRTIs than immunized children $(\mathrm{p}=0.003$, AOR; $2,95 \% \mathrm{CI}: 1.27-3.16)$. Non-exclusively/replacement feeding children were 1.85 times more likely to be affected by acute LRTIs compared with exclusively breastfeeding children $(\mathrm{p}=0.008$, AOR; 1.85, $95 \%$ CI: 1.18-2.91). Similarly, children living in households mainly cooking with unclean fuel had 2.12 times higher odds of developing ALRIs compared with children living in houses mainly cooking with clean fuel $(\mathrm{p}=0.031$, AOR; 2.12, 95\% CI: 1.07-4.19). Additionally, the absence of a separate kitchen had 1.7
Table 3 Environmental factors of acute lower respiratory infections among under-five children attended at WSUTRH, 2019 $(n=414)$

\begin{tabular}{|c|c|c|}
\hline Variable $\mathrm{N}=414$ & Frequency (N) & Percent (\%) \\
\hline \multicolumn{3}{|l|}{ Family size } \\
\hline$\leq 4$ & 205 & $49.5 \%$ \\
\hline$\geq 5$ & 209 & $50.5 \%$ \\
\hline \multicolumn{3}{|l|}{ Smoker in the house } \\
\hline Yes & 25 & $6 \%$ \\
\hline No & 389 & $94 \%$ \\
\hline \multicolumn{3}{|c|}{ Who give care for the child } \\
\hline Mother & 341 & $82.4 \%$ \\
\hline House maker & 73 & $17.6 \%$ \\
\hline \multicolumn{3}{|l|}{ Separate kitchen } \\
\hline Yes & 279 & $67.4 \%$ \\
\hline No & 135 & $32.6 \%$ \\
\hline \multicolumn{3}{|c|}{ Cooking area(kitchen) had window } \\
\hline Yes & 294 & $71 \%$ \\
\hline No & 120 & $29 \%$ \\
\hline \multicolumn{3}{|c|}{ Main household fuel type } \\
\hline Unclean fuel & 357 & $76.2 \%$ \\
\hline Clean fuel & 57 & $13.8 \%$ \\
\hline
\end{tabular}

times higher odds of acute LRTIs in children than having a separate kitchen $(\mathrm{p}=0.021, \mathrm{AOR} ; 1.7,95 \% \mathrm{CI}$ : 1.09-2.65). Finally, children who lived in households that had no window in the cooking room (kitchen) were 1.69 times more likely to be affected by ALRIs compared with those children who lived in houses that had a window in the cooking room (kitchen) ( $\mathrm{p}=0.025$, AOR; 1.69, $95 \%$ CI: 1.07-2.68) (Table 4).

\section{Discussion}

This study showed that the prevalence of acute LRTIs among children who attended WSUTRH was 40.3\% (95\% CI: $35.7-44.9 \%$ ). The findings of this [research are comparable with the demographic and health survey reports of Congo (39.8\%) and Gabon (38.1\%) [12]. However, this finding is higher compared with studies conducted in South West, Ethiopia (28.1\%), [22] Wondo Genet district, Ethiopia (33.5\%), [21] the overall acute LRTIs of sub-Saharan Africa (25.3\%), [12] the Rio Grande do Sul State, Brazil (23.9\%), [29] and Rwanda (5\%) [13]. The possible reason might be the difference in the study setting, difference in socioeconomic status, living conditions and the difference in operational definition to the acute LRTI(type of lower respiratory infections) included. This study was conducted in a health facility and included other acute LRTIs in addition to pneumonia. However, the above studies were conducted in a community setting 
Table 4 Factors associated with acute lower respiratory infections among under five children attended WSUTRH, $2019(n=414)$

\begin{tabular}{|c|c|c|c|c|c|}
\hline \multirow[t]{2}{*}{ Variables } & \multicolumn{2}{|c|}{ Acute lower respiratory infection } & \multirow[t]{2}{*}{$\operatorname{COR}(95 \% \mathrm{Cl})$} & \multirow[t]{2}{*}{$\mathrm{AOR}(95 \% \mathrm{Cl})$} & \multirow[t]{2}{*}{ P-value } \\
\hline & Yes & No & & & \\
\hline \multicolumn{6}{|l|}{ Parents live together } \\
\hline Yes & $151(36.5 \%)$ & $234(56.5 \%)$ & 1 & 1 & \\
\hline No & $16(3.9 \%)$ & $13(3.1 \%)$ & $1.9(0.9-4.1)$ & $2.22(0.99-5.01)$ & 0.054 \\
\hline \multicolumn{6}{|l|}{ History of URTI } \\
\hline Yes & $81(19.6 \%)$ & $92(22.2 \%)$ & $1.59(1.07-2.36)$ & $1.44(0.94-2.21)$ & 0.095 \\
\hline No & $86(20.8 \%)$ & $155(37.4 \%)$ & 1 & 1 & \\
\hline \multicolumn{6}{|l|}{ Immunization status } \\
\hline Immunized for age & $80(19.3 \%)$ & $152(36.7 \%)$ & 1 & 1 & \\
\hline In completed & $16(3.9 \%)$ & $25(6 \%)$ & $1.22(0.61-2.41)$ & $1.12(0.54-2.35)$ & 0.762 \\
\hline Not vaccinated & $71(17.1 \%)$ & $70(16.9 \%)$ & $1.93(1.26-2.95)$ & $2(1.27-3.16)^{*}$ & 0.003 \\
\hline \multicolumn{6}{|l|}{ Breast feeding } \\
\hline Exclusive BF & $104(25.1 \%)$ & $188(45.4 \%)$ & 1 & 1 & \\
\hline Non-exclusive & $63(15.2 \%)$ & $59(14.3 \%)$ & $1.93(1.26-2.96)$ & $1.85(1.18-2.91)^{*}$ & 0.008 \\
\hline \multicolumn{6}{|l|}{ Who care for the child } \\
\hline Mother & $131(31.6 \%)$ & $210(50.7 \%)$ & 1 & 1 & \\
\hline Home maker & $36(8.7 \%)$ & $37(8.9 \%)$ & $1.56(0.94-2.59)$ & $1.64(0.95-2.84)$ & 0.078 \\
\hline \multicolumn{6}{|l|}{ Main cooking fuel } \\
\hline Unclean fuel & $153(36.9 \%)$ & $204(49.3 \%)$ & $2.3(1.22-4.36)$ & $2.12(1.07-4.19)^{*}$ & 0.031 \\
\hline Clean fuel & $14(3.4 \%)$ & $43(10.4 \%)$ & 1 & & \\
\hline \multicolumn{6}{|l|}{ Smoker in the house } \\
\hline Yes & $14(3.4 \%)$ & $11(2.7 \%)$ & $1.96(0.9-4.44)$ & $1.81(0.75-4.33)$ & 0.185 \\
\hline No & $153(36.9 \%)$ & $236(57 \%)$ & 1 & 1 & \\
\hline \multicolumn{6}{|l|}{ Separate kitchen } \\
\hline Yes & $100(24.2 \%)$ & $179(43.2 \%)$ & 1 & 1 & \\
\hline No & $67(16.2 \%)$ & $68(16.4 \%)$ & $1.76(1.16-2.68)$ & $1.7(1.09-2.65)^{*}$ & 0.021 \\
\hline \multicolumn{6}{|c|}{ Window for the kitchen } \\
\hline Yes & $104(25.1 \%)$ & $190(45.9 \%)$ & 1 & & \\
\hline No & $63(15.2 \%)$ & $57(13.8 \%)$ & $2(1.3-3.1)$ & $1.69(1.07-2.68)^{*}$ & 0.025 \\
\hline \multicolumn{6}{|l|}{ Nutritional status } \\
\hline SAM & $10(2.4 \%)$ & $7(1.7 \%)$ & $1.7(0.65-4.57)$ & $2.54(0.88-7.39)$ & 0.087 \\
\hline MAM & $12(2.9 \%)$ & $18(4.3 \%)$ & $1.17(0.55-2.48)$ & $1.15(0.5-2.61)$ & 0.747 \\
\hline Mild/normal & $145(35 \%)$ & $222(53.6 \%)$ & 1 & 1 & \\
\hline
\end{tabular}

$*$ Statistically significant at $p$ value $<0.05$ with $95 \% \mathrm{Cl}$

or included only pneumonia, which will result in a lower prevalence.

In this study, unvaccinated children were 2 times more likely to be affected by acute LRTIs than vaccinated children. Widespread immunizations have been related to the decline of LRTIs in children [3, 30,31]. Similar findings were reported from studies in Gamo Gofa Zone, Ethiopia, [22] Southern Ethiopia, [23] and a systematic review and meta-analysis from the UK [32]. This might be due to the preventive effect of pneumococcal vaccine against streptococcus pneumonia and pentavalent vaccine against homophiles influenza and other respiratory pathogens.
Non-exclusive breast/replacement feed children were 1.85 times more likely to be affected by acute LRTIs compared with exclusively breastfeeding children. This might be due to breast milk contains antibodies that help children fight viruses and bacteria. Additionally, children who are breastfed exclusively for the first six months had a lower risk of acute otitis media, lower respiratory infections, gastroenteritis and diarrhea, and asthma [33, 34]. Other studies conducted in Northwest Ethiopia, [24] Achefer district, Ethiopia, [35] Kersa district, Ethiopia, [25] Gamo Gofa Zone, Southwest Ethiopia, [22] Southern Ethiopia, [23] a systematic review and meta-analysis from the UK, [32] showed similar findings. 
Children living in households mainly cooking with unclean fuel had 2.12 times higher odds of developing acute LRTIs compared with children living in houses mainly cooked with clean fuel. This might be due to the use of unclean fuel might produce high levels of household air pollution, including small soot particles that will penetrate deep into the lungs. Deposited particulate matter may alter airway reactivity and will affect the ability of the lungs to fight pathogens. Exposure is high among women and young children, and as a result, it doubles the risk for childhood pneumonia [36-38]. Studies conducted in Southwest Ethiopia, [22] Gondar city of Ethiopia, [26] Wolaita Sodo, Ethiopia, [27] and Pakistan [39] reported similar findings.

The absence of a separate kitchen had 1.7 times higher odds of childhood acute LRTIs compared with having a separate kitchen. This is due to cooking in the household will result in a higher level of particulate matter concentration, and young children have increased vulnerability to household air pollution due to the longer indoor stay [39]. Similar findings were observed in a study conducted in the Wondo Genet district, Ethiopia, [21] Southwest Ethiopia, [22] and Pakistan [39].

Finally, children who lived in households that had no window in the cooking room (kitchen) were 1.69 times more likely to be affected with acute LRTIs compared with those children who lived in houses that had a window in the cooking room. The kitchen without a window had limited ventilation, and it will increase the exposure of pollutants, particularly for young children who spend much of their time in the kitchen with their mother. This finding is supported by studies conducted in Wolaita Sodo, Ethiopia, [27] Wondo Genet district, Ethiopia [21], Gondar, Ethiopia, [26] and Southwest Ethiopia [22].

\section{Limitation of the study}

This study will be subjected to recall bias and did not consider seasonal variation. Additionally, the diagnosis for acute LRTIs was made based on the physician assessment.

\section{Conclusions}

The prevalence of acute LRTIs among under-five children attending WSUTRH was $40.3 \%$. Unvaccinated children, non-exclusive/replacement feeding, households mainly cooking with unclean fuel, absence of a separate kitchen, and absence of window in the kitchen room showed significant association with acute LRTIs. Therefore, strengthening the environmental sanitation (healthy home environment) and family health (child nutrition, immunization) components of the health extension packages will have a significant contribution to the reduction of under-five acute LRTIs.

\begin{abstract}
Abbreviations
AOR: Adjusted odds ratio; BSc: Bachelors of Science; COR: Crude odds ratio; LRTI: Lower respiratory tract infection; MDG: Millennium development goal; MSc: Masters of Science; OPD: Outpatient department; SDG: Sustainable development goals; SD: Standard deviations; SPSS: Statistical Package for Social Sciences; WSUTRH: Wolaita Sodo University teaching and referral hospital.
\end{abstract}

\section{Acknowledgements}

The authors would like to thank Wolaita Sodo University for funding this study. Our thanks also goes to for all study participants, supervisors and data collectors for their unreserved efforts and willingness to take part in this study.

\section{Authors' contributions}

BW was involved in the conception, design, analysis, interpretation, report and manuscript writing; EA and YA were participated in the design, analysis, interpretation and report writing. ZM was involved in designing the study, analysis, report and manuscript writing. The author(s) read and approved the final manuscript.

\section{Authors' information}

1. Birhanu wondimeneh Demissie is assistant professor in the school of Nursing, College of Health Science and Medicine, Wolaita Sodo University, Wolaita Sodo, Ethiopia.

2. Esayas Aydiko Amele is a lecturer in the school of Nursing, College of Health Science and Medicine, Wolaita Sodo University, Wolaita Sodo, Ethiopia.

3. Yibeltal Asmamaw Yitayew is a lecturer in the department of Paediatrics and Child Health Nursing, College of Medicine and Health Science, Wollo University, Dessie, Ethiopia.

4. Zemen Mengesha Yalew is a lecturer in the department of Comprehensive Nursing, College of Medicine and Health Science, Wollo University, Dessie, Ethiopia.

\section{Funding}

Wolaita Sodo University covered all the cost of data collection, entry, and supervision.

Availability of data and materials

Data will be available upon request from the corresponding author.

\section{Declarations}

Ethics approval and consent to participate

Ethical clearance and approval were obtained from the Institutional Research Ethical and Review Committee of Wolaita Sodo University (approval number 06/320/11). An official letter was submitted, and permission was obtained from WSUTRH to conduct the research. Informed written consent was obtained from all mothers/caretakers after explaining the objectives of the study in detail, and anonymity and confidentially of the data was kept. Respondents have the right not to participate or withdraw from the study at any stage. All study methods were performed in accordance with the 1964 declaration of Helsinki and its later amendments.

\section{Consent for publication \\ Not applicable.}

\section{Competing interests}

The authors declare that there are no conflicts of interest.

\section{Author details}

${ }^{1}$ School of Nursing, College of Health Science and Medicine, Wolaita Sodo University, Sodo, Ethiopia. ${ }^{2}$ Department of Paediatrics and Child Health Nursing, College of Medicine and Health Science, Wollo University, Dessie, Ethiopia. ${ }^{3}$ Department of Comprehensive Nursing, College of Medicine and Health Science, Wollo University, Dessie, Ethiopia. 
Received: 16 February 2021 Accepted: 27 August 2021

Published online: 20 September 2021

\section{References}

1. MedicalNewsToday. Lower respiratory tract infections: symptoms, diagnosis, and treatment. Available at: https://www.medicalnewstoday.com/ articles/324413. Accessed in 2019

2. Biscevic-Tokic J, Tokic N, Musanovic A. Pneumonia as the most common lower respiratory tract infection. Medical Archives. 2013;67(6):442.

3. Boloursaz MR, Lotfian F, Aghahosseini F, et al. Epidemiology of lower respiratory tract infections in children. J Comprehensive Pediatrics. 2013;4(2):93-8.

4. MidlinePlus. Pneumonia in children - community acquired. Available at: https://medlineplus.gov/ency/article/007690.htm\#: :text=Pneumonia\% 20is\%20a\%20lung\%20infection,or\%20another\%20health\%20care\%20 facility. Accessed in 2019.

5. Srinivasa S, Patel S. A study on distribution pattern of lower respiratory tract infections in children under 5 years in a tertiary care centre. Int $J$ Contemporary Pediatrics. 2018;5(2):456.

6. Baghel B, Viswanadham KK. A study of clinical profile and factors associated with acute respiratory infection in paediatric patients at tertiary health care centre. Cough. 2017;315:90.

7. OpenLearnCreate. Communicable Diseases Module: 35. Acute Respiratory Tract Infections. Avialable at: https://www.open.edu/openlearnc reate/mod/oucontent/view.php?id=121. Accessed in 2019.

8. Troeger C, Forouzanfar M, Rao PC, et al. Estimates of the global, regional, and national morbidity, mortality, and aetiologies of lower respiratory tract infections in 195 countries: a systematic analysis for the Global Burden of Disease Study 2015. Lancet Infect Dis. 2017;17(11):1133-61.

9. MCSP. Child Health. Avialable at: https://www.mcsprogram.org/our-work/ child-health/. Accessed in 2019.

10. Cashat-Cruz M, Morales-Aguirre JJ, Mendoza-Azpiri M. Respiratory tract infections in children in developing countries. Paper presented at: Seminars in pediatric infectious diseases 2005 .

11. Wardlaw TM, Johansson EW, Hodge MJ. Pneumonia: the forgotten killer of children. Unicef; 2006.

12. Seidu A-A, Dickson KS, Ahinkorah BO, Amu H, Darteh EKM, Kumi-Kyereme A. Prevalence and determinants of acute lower respiratory infections among children under-five years in sub-Saharan Africa: evidence from demographic and health surveys. SSM-Population Health. 2019;8:100443.

13. Harerimana J-M, Nyirazinyoye L, Thomson DR, Ntaganira J. Social, economic and environmental risk factors for acute lower respiratory infections among children under five years of age in Rwanda. Arch Public Health. 2016;74(1):19.

14. Sonego M, Pellegrin MC, Becker G, Lazzerini M. Risk factors for mortality from acute lower respiratory infections (ALRI) in children under five years of age in low and middle-income countries: a systematic review and meta-analysis of observational studies. PloS one. 2015;10(1).

15. CDC. CDC in Ethiopia. Available at: www.cdc.gov/globalhealth/countries/ ethiopia/pdf/ethiopia.pdf. 2019.

16. EDHS E. demographic and health survey 2016: key indicators report. DHS Program ICF. 2016;363:364.

17. Deribew A, Tessema GA, Deribe K, et al. Trends, causes, and risk factors of mortality among children under 5 in Ethiopia, 1990-2013: findings from the Global Burden of Disease Study 2013. Population Health Metrics. 2016;14(1):42.

18. Murdoch DR, Howie SR. The global burden of lower respiratory infections: making progress, but we need to do better. Lancet Infect Dis. 2018;18(11):1162-3.

19. WHO. Children: reducing mortality. Available at: www.who.int/newsroom/fact-sheets/detail/children-reducing-mortality. 2019.
20. WSU. Referral hospital/Wolaita sodo university. Avaialable at: https:// www.wsu.edu.et/content/referral-hospital. Accessed in 2019.

21. Abuka T. Prevalence of pneumonia and factors associated among children 2-59 months old in Wondo Genet district, Sidama zone, SNNPR, Ethiopia. Curr Pediatric Res. 2017.

22. Lema K, Murugan R, Tachbele E. Prevalence and associated factors of pneumonia among under-five children at public hospitals in Jimma zone South West of Ethiopia, 2018. J Pulmonol Clin Res 2018; 2 (1): 25-31 J Pulmonol Clin Res 2018 Volume 2 Issue. 2018;1.

23. Workineh Y, Hailu D, Gultie T. Determinants of pneumonia among under two children in southern Ethiopia: A case control study 2016. Curr Pediatr Res. 2017;21(4):604-12.

24. Getaneh S, Alem G, Meseret M, et al. Determinants of pneumonia among 2-59 months old children at Debre Markos referral hospital, Northwest Ethiopia: a case-control study. BMC Pulmonary Med. 2019;19(1):147.

25. Geleta D, Tessema F, Ewnetu H. Determinants of community acquired pneumonia among children in Kersa District, Southwest Ethiopia: facility based case control study. J Pediatr Neonatal Care. 2016;5(2):00179.

26. Mekuriaw Alemayehu KA, Sharma HR, Gizaw Z, Shibru A. Household fuel use and acute respiratory infections in children under five years of age in Gondar city of Ethiopia. 2014.

27. Admasie A, Kumie A, Worku A. Children under five from houses of unclean fuel sources and poorly ventilated houses have higher odds of suffering from acute respiratory infection in Wolaita-Sodo, Southern Ethiopia: A Case-Control Study. J Environ Public Health. 2018;2018.

28. Organization WH. WHO guidelines for indoor air quality: household fuel combustion. World Health Organization; 2014.

29. Prietsch SO, Fischer GB, César JA, et al. Acute lower respiratory illness in under-five children in Rio Grande, Rio Grande do Sul State, Brazil: prevalence and risk factors. Cadernos de Saude Publica. 2008;24:1429-38.

30. Bianchini S, Argentiero A, Camilloni B, Silvestri E, Alunno A, Esposito S. Vaccination against paediatric respiratory pathogens. Vaccines. 2019;7(4):168.

31. Jamison DT, Breman JG, Measham AR, et al. Disease control priorities in developing countries. The World Bank; 2006.

32. Jackson $\mathrm{S}$, Mathews $\mathrm{KH}$, Pulanić $\mathrm{D}$, et al. Risk factors for severe acute lower respiratory infections in children-a systematic review and meta-analysis. Croatian Med J. 2013;54(2):110-21.

33. WebMD. Breastfeeding Overview. Available at: https://www.webmd.com/ parenting/baby/nursing-basics\#1. Accessed in 2019.

34. Salone LR, Vann WF Jr, Dee DL. Breastfeeding: an overview of oral and general health benefits. J Am Dental Assoc. 2013;144(2):143-51.

35. Gedefaw M, Berhe R. Determinates of childhood pneumonia and diarrhea with special emphasis to exclusive breastfeeding in north Achefer district, northwest Ethiopia: a case control study. Open J Epidemiol. 2015;5(02):107.

36. Rahut DB, Ali A, Behera B. Domestic use of dirty energy and its effects on human health: empirical evidence from Bhutan. Int I Sustainable Energy. 2017;36(10):983-93.

37. Torres-Duque C, Maldonado D, Pérez-Padilla R, Ezzati M, Viegi G. Biomass fuels and respiratory diseases: a review of the evidence. Proc Am Thoracic Soc 2008;5(5):577-590.

38. WHO. Household air pollution and health. Available at: https://www.who. int/news-room/fact-sheets/detail/household-air-pollution-and-health. accessed in 2019.

39. Khan MSB, Lohano HD. Household air pollution from cooking fuel and respiratory health risks for children in Pakistan. Environ Sci Poll Res. 2018;25(25):24778-86.

\section{Publisher's Note}

Springer Nature remains neutral with regard to jurisdictional claims in published maps and institutional affiliations. 